Landslides (2020) 17:495-498 DOI 10.1007/s10346-020-01361-2 Received: 25 January 2020 Accepted: 27 January 2020 Published online: 4 February 2020 c) Springer-Verlag GmbH Germany part of Springer Nature 2020

\section{Kyoji Sassa \\ Progress of the Fifth World Landslide Forum in Kyoto, Japan, November 2020}

The Fifth World Landslide Forum is organized under the subtitle Implementing and Monitoring the Sendai Landslide Partnerships 2015-2025, Voluntary contribution to the Sendai Framework 20152030, and the Agenda 2030-Sustainable Development Goals.

Date: 2-6 November 2020

Venue: Kyoto International Conference Center, Kyoto, Japan

Organizers: International Consortium on Landslides (ICL); Global Promotion Committee of International Programme on Landslides (IPL-GPC), including: United Nations Educational, Scientific and Cultural Organization (UNESCO); World Meteorological Organization (WMO); Food and Agriculture Organization (FAO); United Nations Office for Disaster Risk Reduction (UNDRR); United Nations University (UNU); International Science Council (ISC); World Federation of Engineering Organizations (WFEO); International Union of Geological Sciences (IUGS); International Union of Geodesy and Geophysics (IUGG); Kyoto University (KU); Japan Landslide Society (JLS); Japanese Geotechnical Society (JGS); Japan Society for Natural Disaster Science (JSNDS); Japan Association for Slope Disaster Management (JASDiM)

Cosponsors: Cabinet office (Disaster Management Bureau); Ministry of Foreign Affairs; Ministry of Land Infrastructure, Transport and Tourism; Science Council of Japan; Japan International Cooperation Agency; Japan Society of Civil Engineers; Agricultural and Rural Engineering Society; some under application

Supporting organizations with finance: Association for Disaster Prevention Research, Kyoto, Japan

\section{Aim}

World Landslide Forum has been organized every 3 years after the first forum in Tokyo, Japan, in 2008. It is a common platform for scientists, engineers, practitioners, and policy makers who are involved in landslide disaster risk reduction to present their latest progress. The Sendai Landslide Partnerships 2015-2025 for Global Promotion of Understanding and Reducing Landslide Disaster Risk was adopted on 16 March 2015 as a voluntary commitment to the United Nations World Conference on Disaster Risk Reduction, held in Sendai, Japan, in 2015. It is a supporting tool for the implementation of the Sendai Framework for Disaster Risk Reduction 2015-2030. The Fifth World Landslide Forum (WLF5) will be the opportunity to achieve a mid-term review and assess the progress made in the implementation of the partnerships. In order to implement further the Sendai Landslide Partnerships 2015-2025 and pursue and enhance thereafter efforts towards landslide risk reduction, the Kyoto 2020 Commitment for global promotion of understanding and reducing landslide disaster risk-A Commitment to the ISDR-ICL Sendai Partnerships 2015-2025, the Sendai Framework for Disaster Risk Reduction 2015-2030, the 2030 Agenda
Sustainable Development Goals, the New Urban Agenda and the Paris Agreement-will be launched at WLF5 by the participating partners as a long-term, broader, and stronger framework for the global landslide risk reduction network (Sassa 2019a, c, d).

Organizing committee

\section{Honorary chairpersons}

Audrey Azoulay, Director-General of UNESCO*; Mami Mizutori, Special Representative of the United Nations Secretary-General for Disaster Risk Reduction*; Petteri Taalas, Secretary-General of WMO*; Qu Dongyu, Director-General of FAO*; David Malone, Rector of UNU; Daya Reddy, President of ISC; Gong Ke, President of WFEO; Qiuming Cheng, President of IUGS; Kathryn Whaler, President of IUGG; Qunli Han, Executive Director of Integrated Research on Disaster Risk (IRDR); Walter Ammann, President and CEO of Global Risk Forum GRF Davos, Switzerland; Juichi Yamagiwa, President of Kyoto University, Japan; Angelo Borrelli, Head of the National Civil Protection Department, Italian Presidency of the Council of Ministers, Italy; Darko But, Director General of the Administration for Civil Protection and Disaster Relief of the Republic of Slovenia, Slovenia; Akifumi Nakao, Director, International Cooperation Division, Disaster Management Bureau, Cabinet Office, Japan; Kazuyuki Imai, Director General of Sabo Department, Ministry of Land Infrastructure, Transport and Tourism, Japan*; Chungsik Yoo, President of the International Geosynthetics Society; Rafig Azzam, President of the International Association for Engineering Geology and the Environment. ( ${ }^{*}$ to be confirmed)

\section{Chairpersons}

Kyoji Sassa (Professor Emeritus, Kyoto University, Secretary General of ICL), Peter Bobrowsky (Geological Survey of Canada, President of ICL), and Kaoru Takara (Kyoto University, Japan, Executive Director of ICL)

\section{Members}

Fausto Guzzetti (Italian National Research Council, Italy), Snježana Mihalić Arbanas (University of Zagreb, Croatia), Nicola Casagli (University of Firenze, Italy), Binod Tiwari (California State University, Fullerton, USA), Matjaz Mikos (University of Ljubljana, Slovenia), Vit Vilimek (Charles University in Prague, Czech Republic), Fawu Wang (Shimane University, Japan), Željko Arbanas (University of Rijeka, Croatia)

\section{Chairpersons of local organizing committee}

Kaoru Takara (President, Japanese Society of Natural Disaster Science), Daisuke Higaki (Chair, ICL Committee of the Japan Landslide Society), Ikuo Towhata (Former President, Japanese Geotechnical Society) 


\section{Secretary generals}

Ryosuke Uzuoka (Professor, Disaster Prevention Research Institute, Kyoto University), Kazuo Konagai (Professor Emeritus, University of Tokyo; Principal researcher of ICL Headquarters), Khang Dang (Research Promotion Officer, ICL)

\section{Forum publication}

1. Journal thematic issue: The review process and standards for the thematic issue "Sendai Landslide Partnerships 2015-2025" are identical to the regular issues of Landslides. The thematic issue may be accessed and downloaded free of charge for 1 month from the middle of October to the middle of November 2020. The author of the accepted paper will be invited as an invited lecturer of WLF5 for a 20-min oral presentation. Those papers that can reach online publication stage in early September 2020 will be included in the thematic issue. Later-accepted papers will be published in one of the regular issues later.

Many papers have been submitted to the thematic issue by the end of 2019. Submitted papers were reviewed by screening editors and some were rejected without in-depth review. Some, which are likely to be accepted, were forwarded to in-depth review. The current state of the thematic issue on 18 January 2020 is 2 papers were accepted, 37 papers are in in-depth review, 2 papers are out for revision, 5 papers are in screening process. A total of 46 papers are candidates. Some papers may be rejected through in-depth review and revision. One issue will include about 15 papers. The thematic issue will be a double-sized issue with 30 papers (around 400 pages).

2. Full-color books: Papers targeted for the full-color books of WLF5 should be submitted to one of the 9 themes through the Editorial Manager for WLF5. Submission link for full-color book is https://www.editorialmanager.com/wlfo/default.aspx The maximum allowable number of pages is 6 and the authors should follow the submission template. The length of talk is $15 \mathrm{~min}$. The maximum number of pages for a keynote lecture (one for a half day), which will be invited by the session or theme coordinator, is 12 . The length of the keynote talk is $20 \mathrm{~min}$.

Those papers that can reach to the ready-to-publish in early April 2020 will be published in one of the 9 full-color books. Later-accepted papers will be published in the electronic proceedings and/or the electronic posters.

3. Electronic proceedings: The printing format of electronic proceedings is one page (title/author/office and abstract) +5-9 pages of 2 PPT slides/page. The total page limit is 6-10. Each session coordinator will review and edit submitted papers as its session volume. All session volumes will be compiled and published by ICL as one electronic book with an ISBN number. Template of E-proceedings is http://wlf5.iplhq.org/wp-content/ uploads/2019/o8/TemplateWLF5.doc-AbstractPPT.docx. Electronic proceedings of each session will be reviewed and edited by the session coordinators and compiled as the session electronic proceeding. The deadline for submission of the session proceedings to the WLF5 secretariat is 31 July 2020. The submission deadline for paper submission is different in each session depending on the review process. (Some sessions set the deadline of paper submission as 31 May 2020). All session proceedings to the WLF5 secretariat will be compiled as WLF5 electronic proceedings with ISBN number.

4. Electronic posters: E-poster is one Ao page electronic poster file (pptx format); template can be downloaded from WLF5 website "http://wlf5.iplhq.org/wp-content/uploads/2019/10/EPoster.pptx". All accepted electronic posters are numbered and uploaded on the web to allow all registered participants to download any of them in advance. Each poster can be cited by its number within the WLF5 electronic posters published by the WLF5 organizing committee. The authors can select a 3min oral presentation, no talk or non-attendance. The deadline for submission is 31 July 2020. The submissions will be reviewed by the $\mathrm{WLF}_{5}$ electronic posters review committee.

\section{Deadline of formal registration}

Accepted papers will be forwarded to the editing and publication process. However, those papers with none of authors registered to WLF5 by the following deadline are removed from the publication process and the speaker programming process.

Full-color books: All papers will be sent to the publisher by 31 May 2020. The deadline of formal registration is 25 May 2020.

Electronic proceedings: All session proceedings will be forwarded to the $\mathrm{WLF}_{5}$ secretariat by 31 July 2020 . The deadline for formal registration is $\mathbf{3 1}$ July 2020.

E-posters: All submitted E-posters will be forwarded to the Eposters evaluation committee by 31 July 2020 . The deadline for formal registration is $\mathbf{3 1}$ July 2020.

Figure 1 summarizes the schedule of review, publication for the thematic issue of Landslides, 9 volumes of full-color books (ISSN books series: ICL contribution to landslide disaster risk reduction), electronic proceedings (summary and $2 \mathrm{PPT} /$ page with ISBN number), electronic poster, registration (early and regular and late registration), and process for launching the Kyoto Landslide Commitment 2020.

\section{Preliminary registration as speakers in WLF5}

Session coordinators and theme coordinators have invited qualified speakers through their networks. Those invited and willing to be speakers of WLF5 have been invited to register in the preliminary registration web informing name, office, country, and preliminary title of speech without payment of registration fee (Sassa 2019b; Sassa et al. 2019, 2020). http://wlf5.iplhq.org/preliminaryregistration/

The web page includes the followings: 1 . Speakers registration, 2. E-poster registration, 3. Sponsor/Exhibition registration, and 4. Non-speaker registration.

Figure 2 presents the speaker registration as of 1 January 2020 and their countries/regions. A total 609 persons from 63 countries/ regions completed the preliminary registration. Name, office, country, and tentative title of talk of each speaker are shown in News/Kyoto Commitment of this issue. The publication of each speaker and tentative title in the Landslides journal will be useful to obtain participation and to raise travel funds to WLF5.

\section{Financial support for participants}

A total of 609 persons from 63 countries/regions have registered to present their research or report in WLF5. 


\begin{tabular}{|c|c|c|c|c|c|c|c|}
\hline \multirow{2}{*}{\begin{tabular}{|c|} 
Activities \\
Publication
\end{tabular}} & \multirow{2}{*}{$\begin{array}{l}\text { Month } \\
\text { Year }\end{array}$} & \multicolumn{2}{|c|}{$1-3$} & 4-5 & $6-7$ & 8-10 & WLF5 \\
\hline & & \multicolumn{6}{|c|}{2020} \\
\hline \multirow{2}{*}{$\begin{array}{l}\text { Journal } \\
\text { thematic Issue }\end{array}$} & Paper submission/review & \multicolumn{4}{|c|}{ Review } & & \multirow{2}{*}{$\begin{array}{l}\text { Invited } \\
\text { Lecturers }\end{array}$} \\
\hline & Journal Publication & & & & & Publication & \\
\hline \multirow{2}{*}{ Full color books } & Paper submssion/review & SB & \multicolumn{2}{|c|}{ Review } & & & \multirow{4}{*}{$\begin{array}{c}\text { Invited } \\
\text { Speakers/ } \\
\text { Speakers }\end{array}$} \\
\hline & Book Publication & & & & & lication & \\
\hline \multirow{2}{*}{$\begin{array}{l}\text { Electronic } \\
\text { Proceedings }\end{array}$} & Abstract+PPT submission & \multicolumn{4}{|c|}{ Submission/Review } & & \\
\hline & E-Proc. Publication & & & & & Publication & \\
\hline \multirow{2}{*}{$\begin{array}{l}\text { Electronic } \\
\text { Posters }\end{array}$} & Submission & \multicolumn{4}{|c|}{ Submission/Review } & & \multirow{2}{*}{$\begin{array}{l}3 \text { minutes talk } \\
\text { or no talk }\end{array}$} \\
\hline & E-Posters WEB Publication & & & & & Publication & \\
\hline \multirow{2}{*}{ Registration } & Speakers & \multirow{2}{*}{\multicolumn{2}{|c|}{$\begin{array}{c}\text { Early } \\
\text { Regstration }\end{array}$}} & \multirow{2}{*}{\multicolumn{2}{|c|}{$\begin{array}{c}\text { Regular } \\
\text { Registration }\end{array}$}} & & \\
\hline & Non-speakers & & & & & Late $\mathrm{F}$ & egistration \\
\hline \multicolumn{2}{|c|}{$\begin{array}{l}\text { Kyoto Landslide Commitment } 2020 \text { (KLC2020) } \\
\text { to be launched at the High-Level Panel Discussio }\end{array}$} & \multicolumn{5}{|c|}{$\begin{array}{l}\text { Signature of KLC2020 on } 19 \text { April } 2020 \text { in } \\
\text { Kyoto university or on } 2 \text { November at } \\
\text { WLF } 5 \text { Venue (KICC), Kyoto, Japan }\end{array}$} & $\begin{array}{c}\text { Launching and } \\
\text { Start of Action } \\
\text { on } 3 \text { November } \\
2020\end{array}$ \\
\hline
\end{tabular}

Fig. 1 Schedule of the Fifth World Landslide Forum

Participation in WLF5 from developing countries is not easy. The list of speakers (name, office, country, and tentative title) is published in News/Kyoto Commitment of this issue. Speakers with "\#” mark requested financial support for the participation and presentation in the forum. The WLF5 organizing committee will support those speakers to promote participation under the following conditions.

\section{Condition of financial supports}

1) Submission of their papers (full papers for full-color books or papers (abstract +PPT) for electronic proceedings to the financial support evaluation team (FSET) of the WLF5 organizing committee and the application form stating necessary financial support type (A, B, C, D, E) by 10 April 2020.
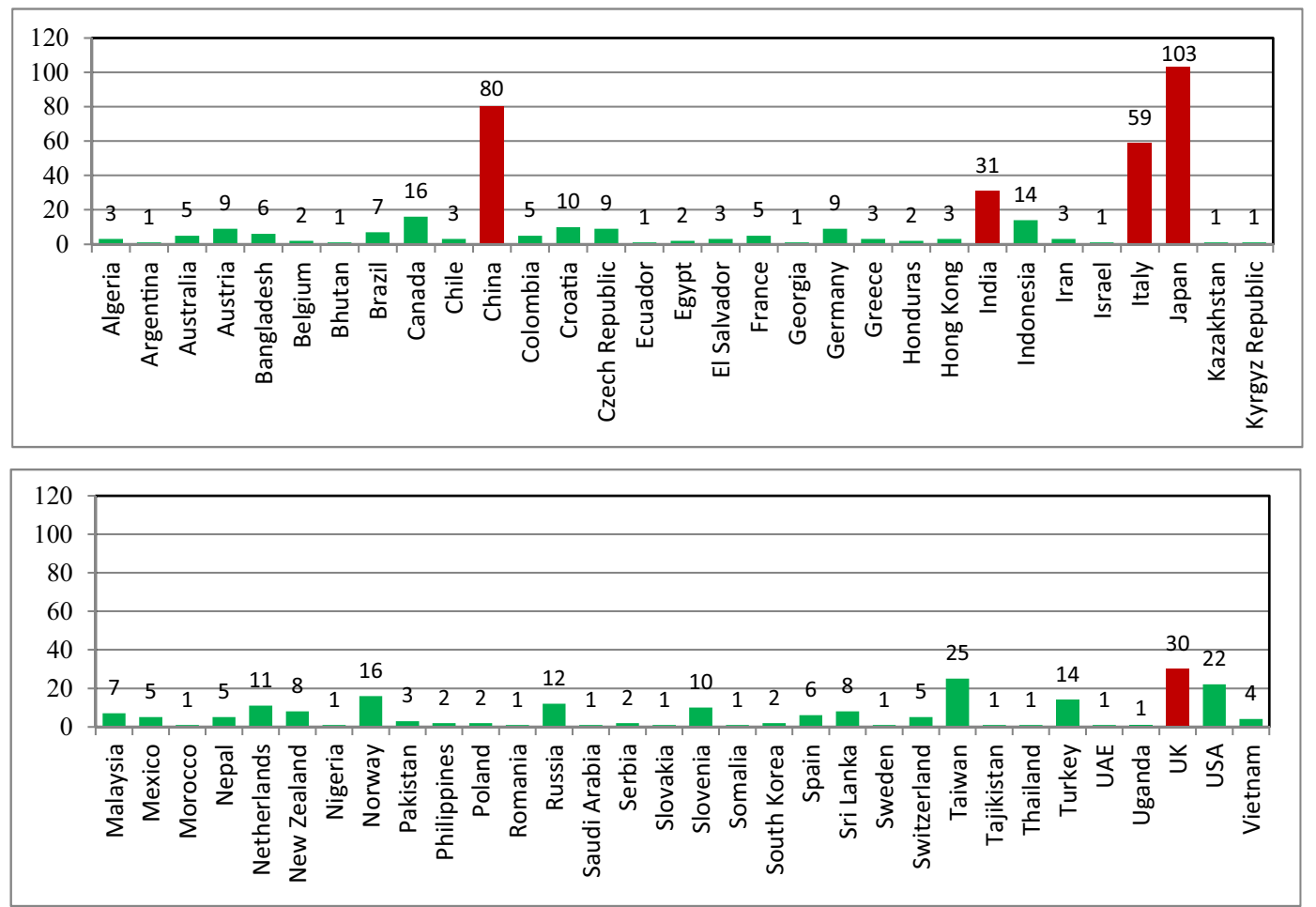

Fig. 2 Preliminary registered persons (as of 1 January 2020) and their countries/regions 
Application form of financial support

Name
Type(s) of support

2) Items of evaluation: quality of paper in the level of country, the necessity of financial support, his/her potential contribution to landslide disaster risk reduction in the future. The result of evaluation will be informed to the applicants by 1 May 2020.

3) Registration through the formal registration page "http:// wlf5.iplhq.org/registration/" and payment of the minimum registration fee (26,000 JPY) by 25 May 2020.

4) Application will be canceled unless the online registration is completed by 25 May 2020.

Type of support

A. Reduction of registration fee to the minimum fee $(26,000$ JPY for students or non-speaker registration).

B. Zero registration fee: The reduced registration fee $(26,000$ JPY) will be refunded.

C. Accommodation support: 50,000 JPY

D. Travel support: $100,000 \mathrm{JPY}$

E. Travel support: $150,000 \mathrm{JPY}$

\section{Call for WLF5 supporting organizations with finance}

Appreciation to WLF5 supporting organizations with finance

1. The organizations are appreciated in Bulletin, WLF5 page in each issue of the Landslides journal

2. The organizations are appreciated in 9 volumes of full-color books and electronic proceeding.

3. Non-speaker registration ticket, reception ticket, and lunch tickets for 4 days will be presented to one representative of each organization.

4. Acknowledgment certificate for each organization will be presented by the ICL President at the closing ceremony on 6 November 2020.
WLF5 organizing committee requests readers of Landslides to cooperate for exploring the WLF5 supporting organizations with finance to support participation from developing countries, and to promote participation of important speakers and advisors for plenary sessions, the World Tsunami Awareness Day event, ICLKLC2020 Intergovernmental Round Table Discussion, and other strategic sessions contributing to the Sendai Landslide Partnerships 2015-2025 and the Kyoto Landslide Commitment 2020.

Potential WLF5 supporting organizations willing to support more than 3000 USD or 300,000 JPY are requested to inform it to the financial support evaluation team (FSET) of $\mathrm{WLF}_{5}$ secretariat;

Email: wlf5-sec@iclhq.org, Subject: FSET/WLF5.

\section{References}

Sassa K (2019a) The Fifth World Landslide Forum and the final draft of the Kyoto 2020 Commitment. Landslides 16(2):201-211

Sassa K (2019b) Registered speakers of the Fifth World Landslide Forum -implementing and monitoring the Sendai Landslide Partnerships 2015-2025 - voluntary contribution to the Sendai Framework 2015-2030 and the Agenda 2030-Sustainable Development Goals. Landslides 16(8):1423-1624

Sassa K (2019c) Journal Landslides, the International Consortium on Landslides, and the Kyoto Landslide Commitment 2020. Landslides 16(9):1623-1628

Sassa K (2019d) The Kyoto Landslide Commitment 2020: first signatories. Landslides 16(11):2053-2057

Sassa K, Guzetti F, Casagli N, Tiwari B, Mikos M, Vilimek V, Bobrowsky P, Arbanas Z (2019) Registered speakers in the Fifth World Landslide Forum. Landslides 16(8):1595-1611

Sassa K, Guzetti F, Casagli N, Tiwari B, Mikos M, Vilimek V, Bobrowsky P, Arbanas Z, Dang K (2020) Registered speakers in the Fifth World Landslide Forum (WLF5). Landslides 17(3) in News/Kyoto Commitment in this issue

K. Sassa $(\square)$

International Consortium on Landslides (ICL)

Kyoto, Japan

Email: secretariat@iclhq.org 